work in the organisation helped us to - align OHS objectives with business objectives of our organisation.

Discussion Periodic and Systematic review of Occupational Health and Emergency Medical Services helps in strengthening them to ensure safe and healthy working conditions for employees.

\section{FIRST PHILIPPINE HOLDINGS SINGLE, MASS CASUALTY, AND DISASTER MEDICAL EMERGENCY RESPONSE STRATEGY}

Joselito L Gapas*. First Philippine Holdings Corporation, Pasig city, Metro Manila, Philippines

\subsection{6/oemed-2018-ICOHabstracts.332}

Introduction First Philippine Holdings (FPH) is involved in geothermal, wind, solar, gas, hydro-electric power operations, construction and real-estate; located all over the Philippines. Although measures are in place to manage risks and prevent injury and illness, a robust medical emergency and disaster response plan (MEDRP) as part of 'recovery measures' was needed in case of control failures.The Philippines is prone to natural disaster (typhoons, earthquakes, etc.). FPH needed a medical disaster response plan that will address needs of employees and dependents, contractors, and host communities post-disaster and recovery.

Methods The corporate MEDRP Guide was developed and implemented. Site plans were reviewed, upgraded and integrated into site's overall response plan. Drills were routinely conducted and reviewed to identify opportunities for improvement. Medical disaster plans leveraged on health resources coming from unaffected company locations. Lessons learned from super-typhoon 'Yolanda' (international name: Haiyan) were incorporated.

Result The MEDRP operates in all major worksites. The tiered and time-based medical and mass casualty response plan has 5 levels: Level 1 - immediate bystander response, Level 2 - first aid response within $4 \mathrm{~min}$, Level 3 - health professional within 1 hour, and Level 4 - casualty in tertiary care facility within 3 hours of the incident. Level 5 covers transfer to a specialist facility if needed via land, helicopter or fixed wing aircraft to designated specialist facilities in Manila. Health components of disaster response plans include: emergency provision of medical services, water supply and sanitation, information and communication systems in coordination with local government

Discussion Developing a robust MEDRP was done via topdown approach working together with site end-users. Generic templates were developed, evaluated, and made specific at the site level ensuring fit-for-purpose and local ownership. The MEDRP is part of the overall ESH management system, managed just like any other business activity.

\section{THE FIREFIGHTER MULTICENTER CANCER COHORT STUDY: FRAMEWORK DEVELOPMENT AND TESTING}

\footnotetext{
${ }^{1} \mathrm{JL}$ Burgess ${ }^{*},{ }^{2} \mathrm{~A}$ Caban-Martinez, ${ }^{3} \mathrm{~K}$ Fent, ${ }^{4} \mathrm{C}$ Grant, ${ }^{1} \mathrm{SC}$ Griffin, ${ }^{2} \mathrm{~N}$ Solle, ${ }^{5} \mathrm{KS}$ Jeong, ${ }^{1} \mathrm{~J}$ Zhao, ${ }^{1} \mathrm{~S}$ Littau, ${ }^{1} \mathrm{E}$ Jacobs, ${ }^{6} \mathrm{~S}$ Jahnke, ${ }^{7} \mathrm{G}$ Horn, ${ }^{1} \mathrm{~J}$ Alesia, ${ }^{8} \mathrm{~J}$ Gulotta, ${ }^{8} \mathrm{P}$ Moore, ${ }^{9} \mathrm{C}$ Popp. ${ }^{1}$ University of Arizona, Tucson, Arizona, USA; ${ }^{2}$ University of Miami, Miami, Florida, USA; ${ }^{3}$ National Institute for Occupational Safety and Health, Cincinnati, Ohio, USA; ${ }^{4}$ Fire Protection Research Foundation, Quincy, Massachusetts USA; ${ }^{5}$ Dongguk University, Seoul, South Korea; ${ }^{6}$ National Development and Research Institutes Inc., New York, USA; 7 Illinois Fire Service Institute, Champaign, Illinois, USA; ${ }^{8}$ Tucson Fire Department, Tucson, Arizona, USA; ${ }^{9}$ Boston Fire Department, Boston, Massachusetts USA
}

10.1136/oemed-2018-ICOHabstracts.333
Introduction Recent epidemiologic studies in the United States have demonstrated excess mortality rates for cancer in firefighters compared with the general population. Firefighters are exposed to multiple carcinogens in the workplace through skin contamination and inhalation. However, we currently do not understand which individual exposures are responsible for cancer in firefighters, the mechanisms by which these exposures cause cancer, or effective means of reducing exposures. Development of a large multicenter firefighter cancer prospective cohort study will address these needs, but the framework for such a study needs to be first developed and tested among a smaller initial set of fire service partners.

Methods The study is harmonising existing firefighter cohort studies in Arizona and Florida, and expanding to include the Boston Fire Department and volunteer and combination fire departments. The study framework components include an Oversight and Planning Board (OPB), a Data Coordination Centre (DCC), an Exposure Assessment Centre (EAC) and a Biomarker Analysis Centre (BAC).

Results The OPB is providing oversight of the study through collaboration with fire service organisations and government agencies. The DCC is developing standardised participant survey data collection tools and analysis protocols sufficient to address the short- and long-term study objectives as well as linkage with long-term outcome data including cancer development. The EAC is developing a carcinogen exposure matrix using self-reported and quantitative exposure measurements to provide improved occupational exposure data for comparison with epigenetic outcomes and eventual cancer outcomes. The BAC is carrying out pilot studies of epigenetic markers of carcinogenic effect and cancer risk comparing firefighters with a range of cumulative exposures and non-firefighter controls.

Conclusion A framework is being established for the subsequent development of a large multicenter cohort study of cancer in the fire service; advance our understanding of firefighter exposures to carcinogens; and help identify biomarkers of carcinogen effect and cancer risk.

\section{QUALITATIVE RISK MANAGEMENT TECHNIQUES IN EMERGENCY PREPAREDNESS AND RESPONSE TO IDENTIFY AND REDUCE OCCUPATIONAL RISK FACTORS}

${ }^{1,2,3}$ DM Zalk*. 'Lawrence Livermore National Laboratory, Livermore, USA; ${ }^{2}$ University of Illinois at Chicago, Chicago, USA; ${ }^{3}$ International Occupational Hygiene Association

10.1136/oemed-2018-ICOHabstracts.334

Introduction Emergency response planners and responders have proper priorities when primarily focusing on life safety and incident stabilisation. Further down the list is the identification, prevention, and management of occupational risk factors for emergency preparedness, surveillance, and response personnel. There is a broad spectrum of potential chemical, biological, and physical exposures for occupations beyond first responders. Understanding and communicating these exposure scenarios and emergency response parameters is necessary for assessing and managing the occupational risk factors, but also for minimising public health consequences.

Methods Control Banding is a qualitative risk assessment strategy for determining work-related risks to establish appropriate control solutions and deliver simplified risk communication. Banding strategies were initially developed for controlling bulk liquid and powder chemical hazards, but have since expanded 